\title{
Functional ecology of wild bees in cities: towards a better understanding of trait-urbanization relationships
}

\author{
Sascha Buchholz ${ }^{1,2} \cdot$ Monika H. Egerer ${ }^{1,2}$
}

Received: 17 October 2019/Revised: 29 May 2020/Accepted: 3 June 2020 /

Published online: 8 June 2020

(C) The Author(s) 2020

\begin{abstract}
A functional ecological understanding of urban wild bee communities is of growing importance especially in regard to biodiversity conservation, ecosystem service maintenance and effective conservation programmes. In this paper, we review and summarize the published literature aiming to inform future research investigations in the growing field of wild bee functional ecology. Specifically, we: (1) review which functional trait-based analyses have been carried out on wild bees in cities thus far; (2) summarize which wild bee species traits have been considered; (3) evaluate any consistent wild bee trait-environment relationships (i.e. urbanization) across studies; and (4) synthesize findings and limitations to inform future research recommendations. We reviewed 48 studies based on a systematic Web of Knowledge search. We found consistent trait characteristics for 'nesting type', 'diet', 'body size', 'sociality' and 'phenology' across studies. More than one third of the studies were descriptive and the majority of studies were located in urban gardens in temperate Europe and North America, calling for more research from underrepresented geographic regions and from the entire spectrum of urban habitat types. Of these studies, only five analyzed functional diversity indices and three studies applied statistics to relate urban wild bee traits to urbanization factors. Future studies should consider trait-based statistics, and could incorporate functional trait-based ecological networks to examine network shifts across urbanization gradients. Our review suggests that we lack generalizable information about wild bee trait and urbanization relationships yet, making conservation recommendations challenging. Therefore, we propose more research that considers methodological recommendations to develop a comparable and comprehensive understanding of how urbanization affects the functional ecology of urban wild bees to link with specific urban conservation measures.
\end{abstract}

Keywords Apidae - Functional diversity - Functional trait - Hymenoptera - Pollinator · Urban ecology

Communicated by Andreas Schuldt.

This article belongs to the Topical Collection: Urban biodiversity.

Monika H. Egerer

monika.egerer@tu-berlin.de

Extended author information available on the last page of the article 


\section{Introduction}

Wild bees have outstanding agricultural, ecological and cultural value as pollinators (Kremen et al. 2007; Lowenstein et al. 2014, 2015) but global populations have plummeted due to among many other factors, land use change and habitat loss, for example due to urbanization (Goulson et al. 2015; Gill et al. 2016; Ollerton 2017). However, urban environments including cities and towns can still provide valuable habitats for diverse wild bee communities (e.g. Baldock et al. 2015, 2019; Threlfall et al. 2015; Hall et al. 2017). Numerous studies have investigated how species taxonomic diversity and community composition are affected by different urban environmental factors such as habitat fragmentation and isolation (Threlfall et al. 2015; Fischer et al. 2016), proportion of impervious surfaces (Geslin et al. 2016a, b), habitat management (Blackmore and Goulson 2014) and host plant cover (Banaszak-Cibicka et al. 2016). Functional analyses that relate the functional diversity and biological traits of wild bees to environmental factors have also grown in number due to the recognition that functional diversity plays an important role in urban bee biology and conservation (Harrison et al. 2018; Martins et al. 2017; Normandin et al. 2017).

Functional approaches in biological conservation that incorporate species traits (e.g. diet breadth) linked to ecosystem functions (e.g. pollination) provide a mechanistic understanding of how biodiversity is related to the environment and how species communities are shaped by environmental constraints (Scheiner et al. 2017). For example, an analysis of the relationships between species' biological traits and environmental factors can help to identify which species from a regional species pool can thrive in certain habitats of interest to maintain ecosystem functioning (Wong et al. 2019). More specifically, cityscapes can act as environmental filters for wild bee species because some biological traits (e.g. dispersal ability) facilitate colonization of urban habitats, while others (e.g. nesting type) can make species more vulnerable to urbanization if, for example, required nesting substrate are lost (Banaszak-Cibicka and Zmihorski 2012; Bartomeus et al. 2013; Fortel et al. 2014). Species maintenance versus species loss within a habitat-and therefore what traits are maintained or lost in the system - can influence the maintenance of ecosystem function, for example the pollination of wild and cultivated plants.

Trait-based ecological knowledge of urban wild bees can inform conservation planning and environmental management of urban habitats to support biodiversity and ecosystem function. For example, at the habitat scale, if we know that wild bees of a certain feeding guild rely on certain habitat features such as perennial vegetation, we can inform city policies on vegetation management within city parks and roadsides (Aronson et al. 2016; Turo and Gardiner 2019). At the landscape scale, if we understand that certain landscape features such as high habitat connectivity promote species of short flight distances that are critical to pollination services (Edelsparre et al. 2018), we can guide city planning to prioritize habitats that connect to other habitats across a city. Aside from biological traits, functional diversity comprises components of biodiversity that are linked to ecosystem processes and therefore adds additional ecological information to typical measures of taxonomic diversity (Magurran and McGill 2011). Here, functional diversity indicates the ecological resilience of biotic communities and quantifies to what extent biotic communities are able to respond effectively to environmental changes (Liebergesell et al. 2016). The relationship between "response traits" and "effect traits" can be an indicator of resilience within a community (Diaz et al. 2013; Oliver et al. 2015), where "response traits" determine the response of species to environmental disturbance, and "effect traits" 
determine species effects on a function. In theory, habitats and regions with higher functional diversity and balanced distributions of response and effect traits are predicted to be more resilient to change, thus maintaining ecosystem functions even where species are lost (Yachi and Loreau 1999; Petchey and Gaston 2006; Oliver et al. 2015).

The body of literature utilizing functional (trait-based) analyses has concordantly grown in recent years, exploring how wild bees of various traits within urban habitats respond to characteristics of urbanization (e.g. Normandin et al. 2017; Buchholz et al. 2020). Some descriptive reviews have described relationships between some common characteristics of wild bees and urban environmental characteristics (Hernandez et al. 2009). However, we need a current updated review of research on wild bee traits in cities from a functional trait perspective to direct future trait-based research and urban biodiversity conservation management. In this paper, we systematically review the published literature on wild bee traits-urbanization relationships to synthesize the research findings regarding the relationship between functional traits and the amount of urbanization in the landscape surroundings - a common variable used in many (if not most) urban bee biodiversity studies. Our goal was to use this review to inform future research directions and approaches on the functional (trait-based) ecology of wild bees in cities. In particular, we aimed to answer the following research questions: (1) What is currently known about wild bee functional traiturbanization relationships and what variables (i.e. bee trait, urbanization variables) are measured? (2) What analytical approaches are used to analyze bee trait-urbanization relationships? (3) Are trait-urbanization relationships generalizable across studies? And (4) what are the knowledge gaps, limitations and biases that future studies should address?

\section{Methods}

We performed a systematic review of the published literature on urban wild bees (prior to 24 March 2020) using the ISI Web of Knowledge (https://www.webofknowledge.com/) database with no restriction on publication year. We used the search string: TOPIC (TS)(bee* OR "wild bee*" OR pollinator* OR bumblebee* OR "bumble bee*” OR "solitary bee*" OR "cave-nesting bee*" OR "pan trap*" OR "mason bee*") AND TOPIC (TS) = (trait* OR "life-history trait*" OR "functional trait*") AND TS = (urban OR city OR cities OR “urban habitat*”). This resulted in 1027 scientific articles, including descriptive papers and reviews. We reviewed all abstracts, and retained only papers that covered analyses on wild bee functional diversity and biological traits in urban and suburban environments. This consisted of removing papers that only focused on abundance and richness of wild bee communities in relation to some measure of urbanization in the surrounding landscape. The reference list of each article was also checked for other relevant publications. We excluded studies that were on pollinators other than wild bees (e.g., bats, beetles, birds, hoverflies, managed bees). In total, 48 studies were included in the review that met our criteria (Table 2 in Appendix 1).

For each study that met our criteria, we collected information about: (a) the authors, year and journal; (b) measures of wild bee functional traits and functional diversity; (c) habitat type and geographic region of origin; (d) statistical approaches used to measure trait-urbanization relationships; and (e) the significant trait- urbanization relationships (Table 2 in Appendix 1). If a study covered more than one habitat type (e.g. meadow, garden, forest), we counted each habitat type in the study and thus the study was counted multiple times (e.g. three). We summarized the traits and trait measurements used across all studies (Table 3 in Appendix 2). For significant trait-urbanization relationships, we 
focused on the effects of urbanization on the respective trait, and recorded whether the effect of urbanization was positive, negative, or had no effect. Collectively, this provided the information about what variables were collected, what relationships exist, and provided the means to examine what relationships may therefore be generalizable. Furthermore, this information provided insight into what knowledge gaps still exist that should be answered in future investigations.

\section{Results}

We reviewed 48 studies that met our criteria. The 48 studies ranged in focal urban habitat type, geographic location, wild bee traits measured, in analytical approach, and in research findings.

The measures of urban wild bee functional traits and diversity varied across the reviewed studies (Table 2 in Appendix 1). Most studies measured the trait 'nesting type' ( $\mathrm{n}=32$ studies), followed by 'body size' $(\mathrm{n}=26)$, 'diet' $(\mathrm{n}=25)$, and 'sociality' $(\mathrm{n}=23)$. Only eight studies included 'phenology' (Table 2 in Appendix 1, Table 4 in Appendix 3). Additional wild bee traits less frequently measured included habitat association $(n=1)$, origin $(n=8)$, mode of pollen transportation $(n=1)$, tongue length $(n=4)$ and zoogeography $(\mathrm{n}=1)$ (Table 2 in Appendix 1).

The reviewed studies varied in focal urban habitat and in geographic breadth. Most studies measured wild bees in urban gardens $(n=23)$, followed by grasslands $(n=16)$. Farms $(n=7)$, forests, and parks were the next most common habitat type $(n=6$ studies each). All other habitat types were underrepresented, consisting of less than five studies (Table 4 in Appendix 3). A majority of the studies were conducted in North America, with 20 studies in the United States of America and three in Canada (Table 4 in Appendix 3). Fifteen studies were from temperate Europe. Four studies took place in South America, including Argentina $(\mathrm{n}=1)$ and Brazil $(\mathrm{n}=3)$. Australia and Africa each had one study.

Of all of these studies we reviewed (48), only 28 used statistical methods to analyze bee trait-urbanization relationships. Regression methods were the most common analytical method employed to analyze shifts in trait frequencies with urbanization variables (Fig. 1). This was followed by descriptive studies of functional trait presence within urban habitats (Table 2 in Appendix 1). Only five studies analyzed functional diversity indices, namely functional dispersion and Rao's average quadratic functional diversity (Braaker et al. 2017; Normandin et al. 2017; Martins et al. 2017; Hung et al. 2019). Three studies applied RLQand fourth-corner analysis to relate wild bee traits to an environmental matrix (Braaker et al. 2017; Harrison et al. 2018; Buchholz et al. 2020).

The wild bee trait-urbanization relationships found also varied considerably, with very few generalizable trends. Fifteen studies found a significant relationship between the amount of urban land cover and wild bee traits, but many studies only focused on one or two traits. Specifically, six studies found a negative relationship between bee body size and increasing urban land cover, whereas eight studies found no relationship. Few studies found a relationship between nesting type and urban land cover: soil- or ground nesters (e.g. Bombus, Lasioglossum and Halictus spp.) were less abundant than above-ground nesters (e.g. some Hylaeus and Megachile spp.) in urban areas in three studies (Geslin et al. 2016a; Sivakoff et al. 2018; Twerd and Banaszak-Cibicka 2019), but more abundant in two studies (Neame et al. 2013; Buchholz et al. 2020). Three studies found that polylectic bees were more common in more urban areas (Carper et al 2014; Martins et al. 2017; Buchholz et al. 2020), whereas one study found that they were less common (Twerd and Banaszak- 
(a)

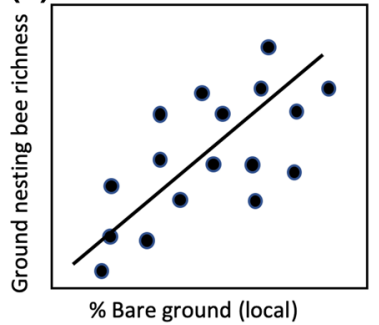

(c)

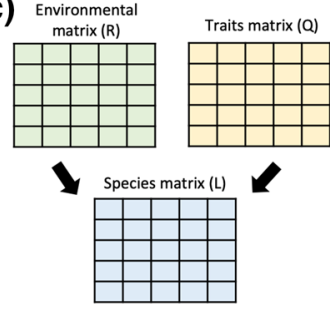

(b)

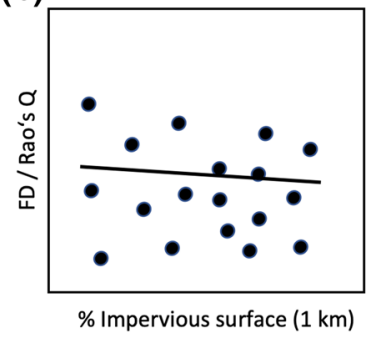

(d)

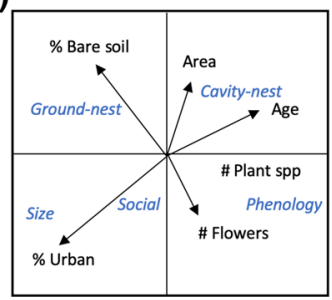

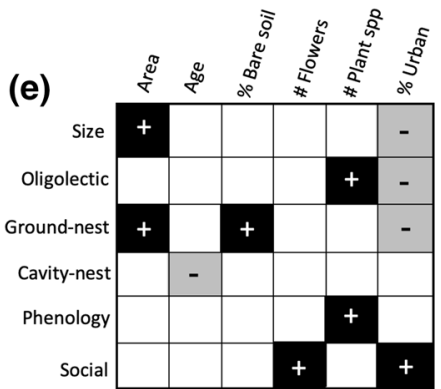

Fig. 1 Hypothetical examples of different methodological approaches to analyze trait-environmental relationships: regression single trait vs. environmental predictor (a), regression functional diversity vs. environmental predictor (b), RLQ-analysis (c, d), fourth-corner analysis (e). Note that data presented are hypothetical, and purely for descriptive purposes and are not trends from specific studies

Cibicka 2019). Two studies found that solitary species (e.g. some Andrena, Nomada, Osmia spp.) were less common in urban areas, whereas social species (e.g. Bombus spp) were more common (Harrison et al. 2018; Banaszak-Cibicka et al. 2018a), though four studies found no relationship between sociality and the urban environment. Last, later flight season was associated with greater urbanization in two studies (Banaszak-Cibicka and Zmihorski 2012; Harrison et al. 2018).

\section{Discussion}

Knowledge of the linkages between bee functional traits and environmental features of urban environments facilitates our understanding of conservation actions, ecosystem function, and how species community composition in urban environments. We found that some wild bee traits including body size and nesting type relate to urbanization factors. Bee body size was often negatively associated to increasing urbanization and soil- or ground nesters were often less abundant than above-ground nesters in urban areas. However, it is difficult to generalize functional trait-urbanization relationships especially due to methodological biases such as differences in study design, quantification of urbanization and trait selection. Functional trait approaches are facilitating greater comparative assessment between studies, which will enable better understanding of how bee communities respond to increasing urbanisation. This is a promising pathway for a better understanding of functional trait shifts, functional understanding of wild bee communities in urban areas, and should be applied in future investigations. 


\section{Trait-based ecology of urban wild bees and analytical approaches used in the literature}

In recent years there has been an increasing number of studies dealing with the functional diversity and trait-urbanization relationships of wild bees in urban environments. Indeed, many of the studies reviewed occurred in the last five to ten years. Most of the studies included 'nesting type', 'diet', 'body size', 'sociality' and 'phenology' as traits, with body size being the most common trait examined. More than a third of all of the studies we reviewed only described bee traits. These studies mostly calculated observed trait frequencies and described how frequencies changed across an urbanization gradient (e.g., with \% urban land cover) or in different urban habitats (e.g. gardens vs. cemeteries), without testing for significant positive or negative relationships with respect to increasing urbanization or differences between environmental factors (Fetridge et al. 2008; Kearns and Oliveras 2009; Sirohi et al. 2015; Lerman and Milam 2016; Cardoso and Goncalves 2018). Regression analyses remain the dominant paradigm in urban wild bee ecological research. These analyses revealed that nesting behavior correlates with garden size (Quistberg et al. 2016: number of cavity species increase with garden size) or urbanization (Geslin et al. 2016a: decrease of ground-nesting bee abundance and species richness), and functional dispersion correlates positively with urbanization (Martins et al. 2017).

There are very few studies addressing functional diversity of wild bees that explicitly apply statistics on functional diversity indices and trait-environment relationships in urban areas, which is surprising given the widely recognised importance of functional analyses when relating biodiversity dynamics to environmental variables (Violle et al. 2007; Loreau 2010; Magurran and McGill 2011). We found only five studies that integrated explicit measures of functional diversity. Martins et al. (2017) analyzed the effects of urbanization and related habitat quality on 'functional dispersion' (the relative abundance of functional traits within a community, cf. Laliberté and Legendre 2010) using linear regression (e.g. Fig. 1b). They found that residential gardens can act as refugia from pesticides and offset the inadequate floral and nesting resources of agricultural landscapes. Semi-natural areas can thus support high levels of diversity and a bee fauna distinct from that of gardens. Normandin et al. (2017) applied Rao's average quadratic functional diversity and their analysis demonstrated that urban cemeteries were less functionally diverse than urban community gardens and urban parks. Buchholz et al. (2020) assessed functional dispersion of wild bee assemblages in grasslands along an urbanization gradient in Berlin but found no direct effect of urbanization. Braaker et al. (2017) found an increase in Rao's average quadratic functional diversity with increasing area and connectivity of urban green roofs, while Hung et al. (2019) showed that functional dispersion decreases in urban habitat fragments relative to natural habitats. Additional functional diversity metrics, such as functional evenness and functional divergence could be assessed with respect to urbanization because both consider other aspects of functional diversity (Schirmel et al. 2012, 2016). For example, urban habitats inhabited by functionally less even species communities may have a decreased productivity and reliability in terms of functioning and are more susceptible to invaders (Mason et al. 2005). Also communities with high functional divergence may have increased ecosystem function as a result of more efficient resource use (Mason et al. 2005). However, both have not been considered in urban wild bee studies to date, although both indices can be easily calculated using open-access statistical software (e.g., the R package $F D$, which can also calculate functional dispersion; Laliberté et al. 2014).

Few studies are going beyond traditional regression methods to analyze bee trait-urbanization relationships. Only two studies (Braaker et al. 2017; Harrison et al. 2018) applied the 
RLQ- and fourth-corner analysis to statistically test trait-environment relationships (e.g. Fig. 1c-e). This method is providing novel insights by making clear which traits are favoured in urban environments, which in turn determines which species become a successful urban dweller and which do not. It can be performed easily in the ade4 R statistical package (Dray and Dufour 2007; Dray et al. 2007) and creates comprehensive outputs including traitenvironmental variable biplots that display the direction and statistical significance of traitenvironment relationships (e.g., Buchholz et al. 2018, 2020; Fig. 1).

\section{Nesting type}

Several of the reviewed studies found lower abundance of ground-nesters in more "urban" habitats in comparison to more "rural" habitats including parks and gardens (Neame et al. 2013; Threlfall et al. 2015; Geslin et al. 2016a; Sivakoff et al. 2018; Twerd and BanaszakCibicka 2019). "Urban" habitats can be defined by, for example higher proportion of impervious surface or residential housing in the surrounding area than rural habitats (Kotze et al. 2011). Large areas of impervious surfaces and little semi-natural habitat in the landscape and compacted or covered soils might be detrimental to ground-nesting species (McIntyre and Hostelter 2001; McFrederick and LeBuhn 2006; Threlfall et al. 2015; Quistberg et al. 2016). These species instead respond positively to increased availability of forests and grasslands in their surroundings at the landscape scale (Pardee and Philpott 2014), and to soils with fine substrates (Kratschmer et al. 2018) and more bare soil available (Quistberg et al. 2016) at the local scale. Also abandoned rodent holes can provide valuable nesting structures for soil nesting bees (e.g. bumble bees) (McFrederick and LeBuhn 2006). As such, urban environments such as urban parks or gardens where rodent activity is prevalent can provide habitat for ground nesters that provide pollination services. Above-ground cavity-nesting wild bees can be more frequent in urban compared with rural habitats (Cane et al. 2006; Matteson et al. 2008; Fortel et al. 2014). Cane et al. (2006) stated that cavity-nesting wild bees are less affected by urbanization than other nesting guilds because urban areas provide numerous suitable nest resources such as fencing, homes, walls and shade trees close to the floral resources of gardens (Pardee and Philpott 2014). However, Threlfall et al. (2015) argued that the nesting success of cavity nesters depends upon the cavity substrate and the ability of species to utilize certain man-made materials. Together, the relationships between nesting traits and environmental factors suggest that habitat management at the local scale is an important filter of bees with certain traits related to nesting behaviour. Specifically, managing ground surface substrate and diversity as well as tree or tree-like cavities at the local and landscape scale is important for supporting bee species of more diverse nesting behaviours across urbanization gradients.

\section{Diet}

There is no strong consensus on the relationship between urbanization and wild bee dietrelated traits, including oligolecty (i.e. specialized feeders) and polylecty (i.e. generalist feeders). Two studies found no differences between urban and natural habitats regarding wild bee diet (Gotlieb et al. 2011; Wray et al. 2014). Although oligolectic wild bees may be abundant in some urban habitats such as gardens or parks (Frankie et al. 2005; BanaszakCibicka et al. 2018a, b; Hamblin et al. 2018; Lerman and Milam 2016), most studies found an overall reduction in the abundance and species richness of oligolectic wild bees in cities in comparison to rural or natural/semi-natural areas (Cane 2005; Cane et al. 2006; Fetridge 
et al. 2008; Banaszak-Cibicka and Zmihorski 2012; Zurbuchen and Müller 2012; Kratschmer et al. 2018, Twerd and Banaszak-Cibicka 2019) while polylectic species are more abundant in cities in comparison with rural landscapes (Matteson et al. 2008; Ahrné et al. 2009; Antonini et al. 2013; Hausmann et al. 2016; Jedrzejewska-Szmek and Zych 2013; Deguines et al. 2016). These studies propose that this relationship is likely due to the abundance of ornamental plant species in cities that attract pollinators. Collectively these results suggest that plant-pollinator networks seem to be less diverse in cities because they comprise few specialists and many generalists (Martins et al. 2017).

\section{Body size}

There is some evidence across the literature that urbanization filters for small-bodied bees. Some studies showed that wild bees are smaller in urban compared with rural habitats (Ahrné et al. 2009; Banaszak-Cibicka and Zmihorski 2012; Wray et al. 2014; Hamblin et al. 2018; Eggenberger et al. 2019), and large-bodied species are often scant in cities (e.g., [Metro-Detroit Region, MI, USA] Glaum et al. 2017; [Poznan, Poland] BanaszakCibicka et al. 2018a, b).

Eggenberger et al. (2019) analyzed urban bumblebee species and stated that smaller body sizes in cities can be related to effects of resource availability and heat islands effects on species physiology. Resource availability is often limited in urban sites with high amounts of impervious surfaces in the surroundings (e.g., Colla and MacIvor 2016), and during species larval stages undernutrition can lead to smaller body sizes in adults (Sutcliffe and Plowright 1988; Schmid-Hempel and Schmidt-Hempel 1998). Furthermore, smaller body sizes in urban wild bee populations may be related to urban heat.

Negative relationships between bee species body size and increasing urbanization found in these studies may be related to bees responding to habitat and resource availability at small spatial scales. Body size of wild bees is also linked to foraging range, in which largebodied species are able to fly longer distances in search of resources while smaller bees have smaller foraging ranges (Araújo et al. 2004; Stang et al. 2006; Greenleaf et al. 2007). Small-bodied bee species might need less pollen and nectar to successfully reproduce (Cane et al. 2006). Also, there may be no need to fly long distances to forage in cities because of the very diverse and abundant floral resources in close proximity to one another often planted in ornamental landscapes including home gardens, community gardens, and city parks (Lowenstein et al. 2014; Hülsmann et al. 2015; Hall et al. 2017).

\section{Sociality}

There is no generalizable trend in sociality across urban habitats. Some studies found social species are more frequent in urban habitats surrounded by a high amount of impervious cover compared to suburban or rural sites (Harrison et al. 2018; Banaszak-Cibicka et al. 2018a; Kratschmer et al. 2018). Several studies found no significant urbanization effects on the abundance of eusocial species (Zanette et al. 2005; Carper et al. 2014; Guenat et al. 2019). Urban areas may provide more diverse nesting substrate for social colony building species that can utilize features of the built environment (Cane et al. 2006). In addition, the presence of honey bees in urban areas may also negatively impact the foraging and reproductive capacity of solitary species (e.g. Ropars et al. 2019), thus outcompeting solitary species. However, given the limited data further work is needed to test these hypotheses around sociality and urbanization. 


\section{Phenology and seasonality}

Although there are no generalizable relationships between phenology and seasonality and urbanization, some studies suggest that wild bees with later spring emergence dates and later flight seasons seem to be better-adapted to urban environments. For example, Harrison et al. (2018) observed increased abundance of wild bees with late flight seasons in urban habitats relative to forest habitats, due to the presence of late-blooming plants. Banaszak-Cibicka and Zmihorski (2012) found that wild bees with later emergence dates prevail in urban settings while spring-emerging bees may be negatively affected by urbanization due to urban warming if this changes flowering phenology (Wray et al. 2014; Harrison and Winfree 2015). Spring-emerging wild bees that overwinter as adults might lose more weight before emergence than summer-emerging bees overwintering as larva, likely because of their higher metabolic activity in response to warmth (Fründ et al. 2013). Some pollinators may adapt and lengthen their flight season in urban habitats, as found for Bombus terrestris, which collected nectar and pollen during a mild winter (Stelzer et al. 2010) and also Harrison et al. (2019) found longer flight seasons for wild bees in urban habitats. Floral resources provided by nonnative species flowering at different times than natives or blooming for long periods may extend activity periods of wild bees (Harrison and Winfree 2015).

\section{Limitations and critical reflection}

Trait-based ecology of wild bees in urban environments has received much attention in recent years, but we do not have strong evidence of generalizable trait shifts with increasing urbanization. In this section, we discuss potential reasons for inconsistencies and multi-directional responses between bee traits and urbanization across the current literature. Specifically, we focus on three research methodological biases that limit our understanding: (1) bias in wild bee species traits; (2) bias in sampling design; and (3) bias in statistical approach.

\section{Trait data bias}

Appropriate trait selection is mandatory for sound trait-based ecology (Wong et al. 2019). In particular, the incorrect assumption that all traits are "functional" may lead to false conclusions. Trait selection by researchers affects the outcome of any study, and should be carefully selected and justified by researchers. Brousseau et al. (2018) state that many studies focus on for example body size, phenology or sociality but these traits are sometimes difficult to relate to particular environmental filters. Rather, future studies should assess traits that better relate wild bee species occurrence to particular stressors of the urban environment (Table 1), and may be "response" or "effect" traits to infer community response and ecosystem function resilience to disturbance (Oliver et al. 2015). For example, we recommend that studies should assess desiccation resistance of wild bee species, water content, and temperature tolerance because cities are "heat islands" (Gago et al. 2013). Voltinism—which is the number of generations in a single year - could also be an important trait because cities provide a longer vegetation period and longer access to resources (Dallimer et al. 2016). This could promote bivoltine species in urban environments (Iwasa et al. 1992) and enable wild bees to have an additional generation (Leong et al. 2016).

It is important to refer to reliable and standardized trait information to ensure comparable trait-based analyses (Wong et al. 2019). Yet comprehensive databases for wild bee traits are 
Table 1 List of (a) types of wild bee species traits and (b) examples of types of function traits that were selected in reviewed studies. and their (c) hypothesized relationship to ecological function/life history

\begin{tabular}{|c|c|c|}
\hline $\begin{array}{l}\text { (a) Trait } \\
\text { type }\end{array}$ & (b) Example trait & (c) Example ecological function \\
\hline \multirow[t]{3}{*}{ Behavior } & Nesting type & Related to habitat and substrate preferences \\
\hline & Phenology & $\begin{array}{l}\text { Activity time of species determines for example the duration of } \\
\text { access to resources }\end{array}$ \\
\hline & Sociality & Degree of interactive behavior with other members of its species \\
\hline Ecology & Habitat & Number of habitats inhabited or habitat preferences \\
\hline Foraging & Diet & Determines the quality and range of resources \\
\hline \multirow[t]{2}{*}{ Geography } & Origin & Describes if a species is native or exotic \\
\hline & Zoogeography & Global distribution \\
\hline \multirow[t]{3}{*}{ Morphology } & Body size & Related to amount and composition of resources used \\
\hline & Pollen transportation & Affects the amount of pollen intake \\
\hline & Tongue length & Related to amount and composition of resources used \\
\hline Physiology & $\begin{array}{l}\text { Drought/temperature } \\
\text { affinity }\end{array}$ & Ability to withstand dry conditions \\
\hline
\end{tabular}

Traits (according to Moretti et al. 2017; Brousseau et al. 2018)

missing to date. Databases that do exist cover only a narrow geographical range [e.g. Central Europe; (Homburg et al. 2014)]. Also the source of trait information can result in data bias since traits are often measured or assessed differently (see Table 3 in Appendix 2) or trait information is taken from inconsistent references which is even true in one reference area (e.g., Amiet 1996, Amiet et al. 2001, 2004, 2007, 2012 vs. Westrich 2019). The effects of intraspecific variation can also affect reliability of trait information and therefore must not be ignored (Wong et al. 2019). Intraspecific variation in phenotypic traits within a species can result from local adaptations or phenotypic plasticity (Des Rocher et al. 2018) and was found in pollinator populations (Classen et al. 2017; Warzecha et al. 2016), even in urban environments (Eggenberger et al. 2019). Effects of intraspecific trait variation are often comparable to species effects (Des Rocher et al. 2018) and therefore should be considered when interpreting trait shifts.

\section{Sampling design bias}

The wide differences in study methodology and design across the urban wild bee ecological literature produces several, what we consider, sampling design biases. We categorized three types of sampling design biases: an environmental data bias, a study system bias, and a sampling method bias.

\section{Environmental data bias}

Across the current literature there is a bias in the environmental data, specifically around the metrics of urbanization. Our analysis is hinged upon the relationship between urbanization at the landscape scale and wild bee traits, yet the "urbanization" variable is not consistently measured across studies. In several studies, the quantification of urbanization was expressed as either (a) proportion of impervious surface in a buffer around the study site (Buchholz et al. 2020; Eggenberger et al. 2019), (b) residential land use (Lerman and Milam 2016), or (c) proximity to urban development (Kearns and Oliveras 2009). A lack of a definition of urbanization or 
measurement of urbanization is a drawback because environmental effects are not comparable across different studies which hinders generality and synthesis of functional relationships. Furthermore, only a few studies covered the whole gradient from urban to rural sites with a quantification of urbanization (mostly proportion of impervious surface in a buffer around the study site) (e.g., Buchholz et al. 2020, Eggenberger et al. 2019, Guenat et al. 2019). The majority of studies compared sites only along a narrow gradient (e.g., Carper et al. 2014, Martins et al. 2017, Twerd and Banaszak-Cibicka 2019), sites within one urbanization category (e.g., Pardee and Philpott 2014, Threllfall et al. 2015, Quistberg et al. 2016), or without properly defining urbanization (e.g., Geslin et al. 2016b, Sivakoff et al. 2018, Harrison et al. 2019). In addition are the possible interactions overlooked between urbanization land cover factors and other abiotic (e.g. urban heat) (Hamblin et al. 2017) or biotic (competition with honey bees) (Ropars et al. 2019) drivers and also habitat quality can modulate relationships (Buchholz et al. 2020).

\section{Study system bias}

Inconsistencies across different studies may arise either from a geographical bias or a habitat bias of the wild bee research to produce a study system bias. First, most studies are conducted in the Global North. This suggests not only a geographical bias, but also a climate regime bias, which is relevant because temperature is an important driver of trait shifts (Hamblin et al. 2017). Also, a geographical bias may result from several studies from one research group that may bias the literature towards that very specific system or geographic region.

Furthermore, our review suggests a habitat bias since most studies have been conducted in gardens, which often have high ornamental richness and abundance and therefore are different in vegetation composition from urban wastelands, lawn or cemeteries (Francis and Chadwick 2013) —all habitats that were underrepresented in our review. Ideally there is a need for equal representation to draw conclusions.

\section{Sampling bias}

Sampling method can strongly affect results in trait research because sampling methods bias detection towards particular species and away from others (Wong et al. 2019). Some researchers used window traps, bee bowls, direct observation, hand sampling, or photographic surveys. Sweep netting may produce biases because observers may not be the same, or because sweep netting is not possible at all sites simultaneously. Observational and/or photographic surveys can produce biases because it is very difficult to generate species-level identification needed for functional trait analyses. Although pan trapping may have biases in which species it attracts (Roulston et al. 2007) this method may reduce observer bias and any temporal bias, and can produce data at the trait level.

\section{Low replication bias}

In ecological research, there is often a trade-off between replication (number of study sites) and sampling intensity (number of times visited, duration of trap exposition) (e.g., Coddington et al. 1991; Oksanen 2001). Our review suggests that it is often challenging to find a sufficient number of suitable sites in cities to sample for wild bees because replication per urbanization category or habitat is often below five and in many cases unbalanced. To maximize replication, we recommend to, on the one hand, focus on a standardized type of model ecosystem (e.g., von der Lippe et al. 2020) and, on the other hand, particularly 
compare urban and rural sites and to go without intermediate urbanization levels. If pan trap methods are applied, such a focused study design can ensure high replication with an appropriate sampling intensity.

\section{Statistical bias}

Most studies on wild bee traits are descriptive studies that prevent generalizations because of missing statistical analyses or rigor. Thus, observational data of wild bee species of various life histories might be reported or interpreted as effects without testing for statistical significance. In addition, several studies compared different habitat types in the urban context, for example forest vs. agriculture vs. urban sites (Harrison et al. 2018), vacant lots vs. community gardens (Sivakoff et al. 2018) or forested vs. agricultural sites (Harrison et al. 2019). These comparisons may distort or dilute urbanization effects because agricultural and urban sites are simply very different, and therefore give more weight to habitat type or system effects. The type of urban land-use (or biotope, habitat, ecosystem), is often a major driver for patterns in urban wild bee assemblages (Baldock et al. 2019; Dylewski et al. 2019; Egerer et al. 2020). Therefore, studies that use different habitat types or biotopes, rather than standardized types of model ecosystems, prevent us from actually distinguishing urbanization effects from effects that would otherwise be masked by site-specific conditions.

\section{Future directions}

We conclude by proposing three main knowledge gaps: (1) extending urban geographical and study system breadth; (2) increasing consistency and transparency across trait-based research and accounting for interspecific trait variation; and (3) linking urban wild bee traits to ecosystem function.

First, there is an urgent need for studies from Africa, Asia, and the Mediterranean region of Europe. South America and Australia are also underrepresented, considering these areas contain biodiversity hotspots. In addition, most studies have focused on wild bee traits within urban gardens, but there are many more valuable habitat types in cities that should be investigated. In particular, vacant lots and wastelands with spontaneous vegetation, amenity grasslands and even roadside greenery should be considered as these habitat types contribute considerably to the urban green infrastructure and have been shown to harbour functionally diverse wild bee communities.

Second, future studies should increase the consistency of urban wild bee trait-based data collection, analysis and transparency. Here, investigators should collect primary data on traits in a continuous form because categorical traits are less suitable to reflect changes in trait-environment interaction (Lavorel and Garnier 2002). This approach can best capture intraspecific trait variation present in most terrestrial invertebrates but largely underexplored (Didham et al. 2016). Furthermore, all of this trait data should be open-source for all researchers to inform their investigations and results (see Wong's (2019) recommendations for the development of terrestrial arthropod databases). Once trait data are collected, studies should apply appropriate trait-based statistic approaches to explicitly analyze the relationships between wild bee functional traits and urban environmental variables, rather than simply present observational data. Regression, or even better, RLQ- and fourth-corner analyses are very useful and widely accepted statistical tools in ecology to directly statistically correlate environmental variables to trait frequencies by combining trait, species, and environmental data matrices (Dray et al. 2014). This may better inform the currently 
missing generalizable conclusions regarding trait shifts with environmental variables in urban areas. Indeed, our review's sample size was limited to half of all studies that met our initial search criteria due to the lack of rigorous statistical methods.

Third, future research should relate urban wild bee traits to ecosystem function and link traits to pollination of wild plant species along with cultural plants prevalent in cities (e.g. ornamental and food crops). Linking these traits to a function, and subsequently likely to an 'ecosystem service', can also better guide or heighten people's awareness about the role of wild bee (functional) diversity in their cities.

\section{Conclusions}

It is imperative to elucidate the impacts of urbanization on the functional ecology of wild bees as cities grow across the world and arthropod biodiversity declines. Yet, there is much research that still needs to be done to consistently link functional traits with urban environmental factors using modern statistical approaches in functional ecology, and to do so in multiple and diverse geographic contexts including analyses of multiple trait responses. As we have discussed in this review, we lack generalizable information about wild bee trait and urbanization relationships to actually inform pollinator conservation policies and conservation planning in cities. Furthermore, most studies lack a clear link between traitbased ecology and wild bee conservation in urban areas. If implications are formulated at all, they are very general and relate to how to increase taxonomic diversity in cities (e.g., protection across a wide range of habitats, limit the frequency of mowing, establishment of flower-rich open areas). To what extent certain traits or functional diversity can be promoted is often not discussed. Trait-based ecology of urban wild bee assemblages will be important for more targeted species protection, and future studies must clearly integrate functional (trait-based) ecology into the conservation context. Our review suggests that certain traits (i.e. oligolecty) may make species more vulnerable to urbanization or local extinction in urban environments. Species with traits negatively associated with urbanization should be prioritized in species protection measures. More research in urban areas worldwide is needed to guide urban policies and conservation plans that conserve wild bee communities that are functionally diverse as well as species diverse. Thus, it is an exciting and critical time for research on the functional ecology of wild bees in cities.

Acknowledgements We acknowledge support by the German Research Foundation and the Open Access Publication Fund of TU Berlin (Projekt DEAL). We thank four reviewers for providing helpful comments that significantly improved the manuscript. This work was funded by the German Federal Ministry of Education and Research (BMBF) within the Collaborative Project "Bridging in Biodiversity ScienceBIBS" (funding number 01LC1501A-H).

Open Access This article is licensed under a Creative Commons Attribution 4.0 International License, which permits use, sharing, adaptation, distribution and reproduction in any medium or format, as long as you give appropriate credit to the original author(s) and the source, provide a link to the Creative Commons licence, and indicate if changes were made. The images or other third party material in this article are included in the article's Creative Commons licence, unless indicated otherwise in a credit line to the material. If material is not included in the article's Creative Commons licence and your intended use is not permitted by statutory regulation or exceeds the permitted use, you will need to obtain permission directly from the copyright holder. To view a copy of this licence, visit http://creativecommons.org/licenses/by/4.0/.

\section{Appendix 1}

See Table 2. 
2792

Biodiversity and Conservation (2020) 29:2779-2801

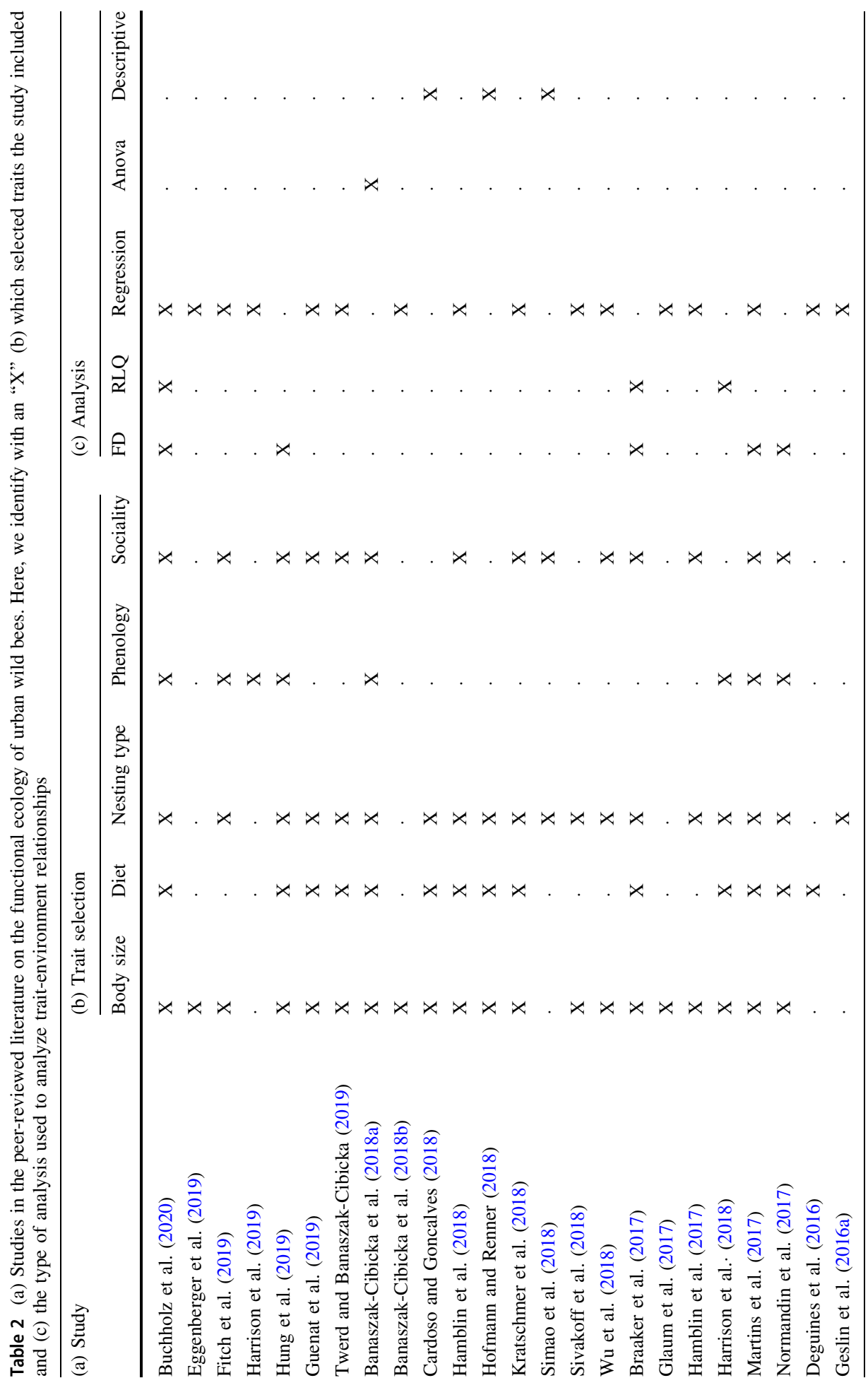

Springer 
Biodiversity and Conservation (2020) 29:2779-2801

2793

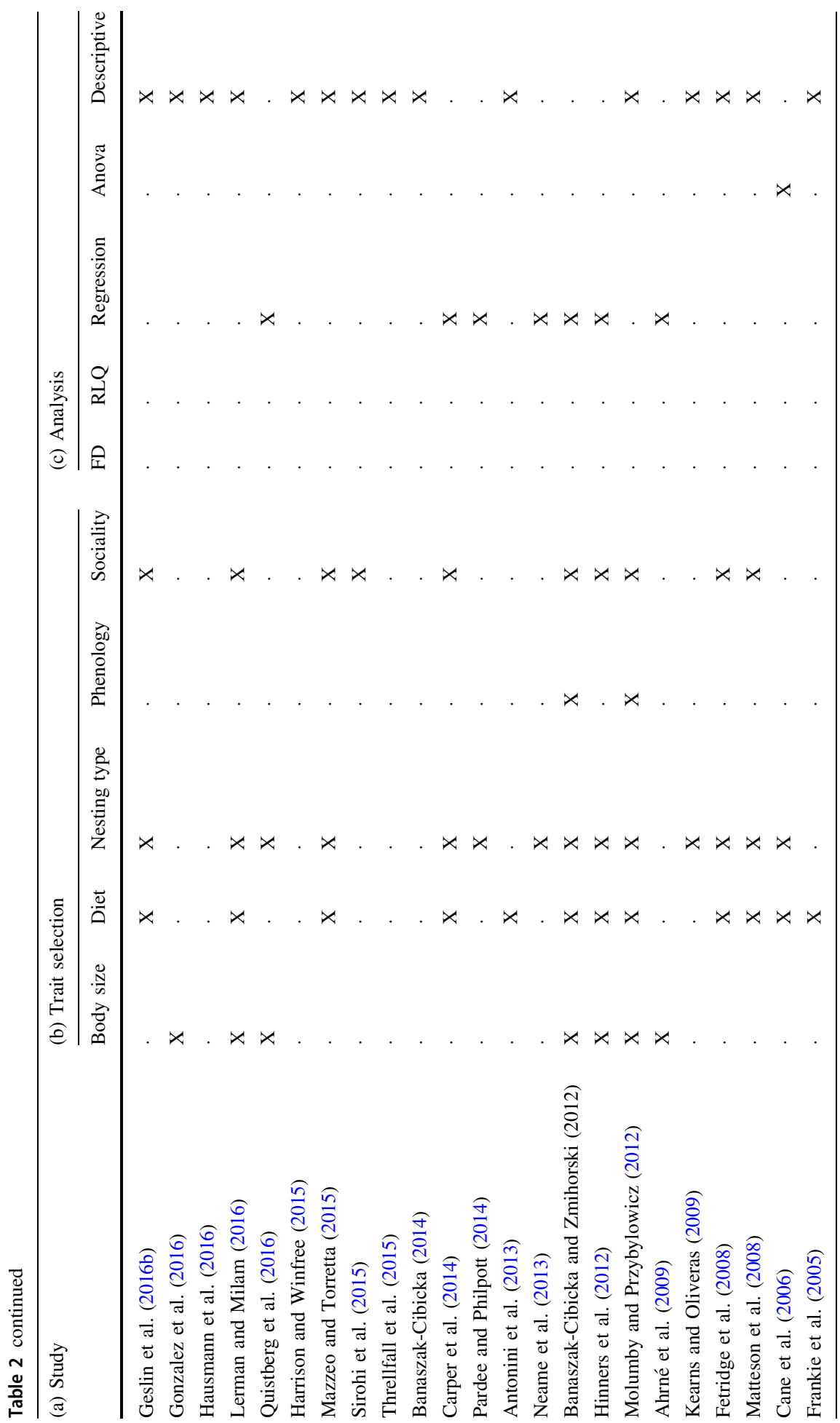

Springer 


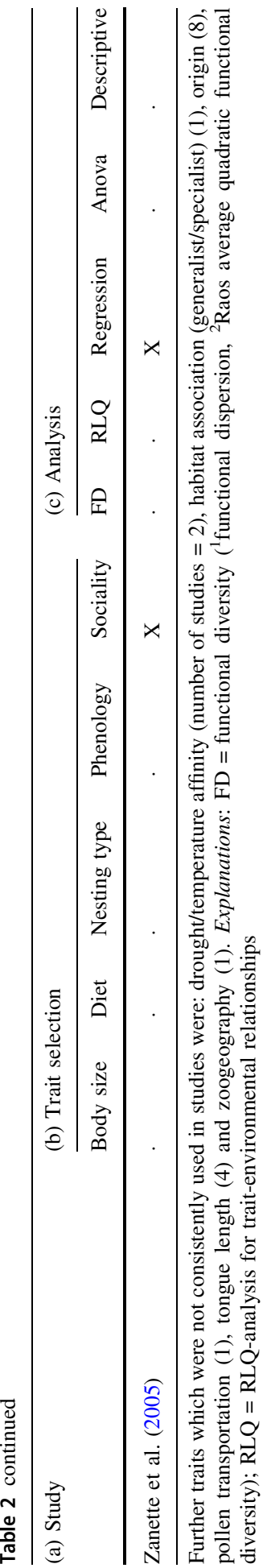

\section{Springer}




\section{Appendix 2}

\section{See Table 3.}

Table 3 (a) Wild bee traits and (b) types of alternative trait names that were used in the reviewed studies and (c) corresponding trait categories used by the authors to categorize bee traits

\begin{tabular}{|c|c|c|}
\hline (a) Trait & (b) Alternative trait name & (c) Trait categories \\
\hline Body size & Inter-tegular distance & $\begin{array}{l}\text { Metric; } \\
\text { Classes: small }<1.5 \mathrm{~mm} \text {, medium } \\
\text { 1.6-3 mm, large }>3.1 \mathrm{~mm}) ; \\
\text { Classes: small }<7.5 \mathrm{~mm}, \text { medium } \geq 7.5- \\
\quad \leq 11.5 \mathrm{~mm} \text {, large }>3.1 \mathrm{~mm}) ; \\
\text { Classes: small } \leq 1.5 \mathrm{~cm}, \text { large }>1.5 \mathrm{~cm}\end{array}$ \\
\hline Diet & $\begin{array}{l}\text { Diet breadth, dietary specialisation, floral } \\
\text { specificity, (mean) flower specialisation, } \\
\text { pollen specialisation, trophic habits, } \\
\text { trophic niche }\end{array}$ & $\begin{array}{l}\text { Community specialisation Index; } \\
\text { Oligolectic, polylectic; } \\
\text { Generalist, specialists } \\
\text { Self measured (mean floral specialisation, } \\
\text { trophic niche) }\end{array}$ \\
\hline Nesting type & $\begin{array}{l}\text { Nest substrate, nesting guild, nesting } \\
\text { habitat, nesting place, nesting preference, } \\
\text { nesting site }\end{array}$ & $\begin{array}{l}\text { Aboveground/belowground-nesting } \\
\text { Cavity, hive, hard wood, pith, soil, soft } \\
\text { wood } \\
\text { Cavity/pith, cavity, wood, pith, soil, soft/ } \\
\text { rotting wood, undet; } \\
\text { Ground nesting, cavity nesting, } \\
\text { cleptoparasite; } \\
\text { Soil, wood, pithy stems, cavity, hive; } \\
\text { Excavator in woody substrate, excavator in } \\
\text { the ground, cleptoparasitic, nests in pithy } \\
\text { stems of plants, nest in pre-excisting } \\
\text { cavities; } \\
\text { Ground nesters, cavity nesters, brood } \\
\text { parasites, flower flies, managed } \\
\text { pollinators; } \\
\text { Ground, cleptoparasite cavity below } \\
\text { ground, cavity above ground, social } \\
\text { parasite, carder }\end{array}$ \\
\hline Origin & & $\begin{array}{l}\text { Exotic, native; } \\
\text { Introduced vs native }\end{array}$ \\
\hline Phenology & & $\begin{array}{l}\text { Activity levels in the spring, summer and } \\
\text { fall } \\
\text { Month of first acitivity }\end{array}$ \\
\hline $\begin{array}{l}\text { Pollen } \\
\text { transportation }\end{array}$ & & $\begin{array}{l}\text { Accidental, leg and body, corbiculae, legs } \\
\text { only, underside, crop }\end{array}$ \\
\hline Sociality & Behavior, social behavior & $\begin{array}{l}\text { Solitary, social, parasitic } \\
\text { Solitary, primitively eusocial; } \\
\text { Solitary, parasitic, eusocial, subsocial; } \\
\text { Solitary or communal, parasitic, eusocial, } \\
\text { subsocial; } \\
\text { Solitary, eusocial, cleptoparasite }\end{array}$ \\
\hline Tongue length & & Short, medium, long \\
\hline
\end{tabular}




\section{Appendix 3}

See Table 4.

Table 4 (a) Urban habitat types investigated in the reviewed studies and the respective number of reviewed studies; and (b) geographic location (continent and country) in which the reviewed studies took place and the respective number of reviewed studies

\begin{tabular}{lcllr}
\hline (a) Habitat & Number of studies & (b) Continent & Country & Number of studies \\
\hline Bush & 3 & Africa & Ghana & $\mathbf{1}$ \\
Cemetery & 1 & Asia & China & 1 \\
Crops & 1 & & Turkey & 1 \\
Farm & 7 & & Total & $\mathbf{2}$ \\
Forest & 6 & Australia & Australia & $\mathbf{1}$ \\
Garden & 23 & Europe & Austria & 1 \\
Golf course & 1 & & France & 3 \\
Grassland & 15 & & Germany & 1 \\
Lawn & 3 & & Poland & 5 \\
Park & 6 & & Sweden & 1 \\
Roof top & 3 & & Switzerland & 2 \\
& & & UK & 1 \\
& & & Total & $\mathbf{1 4}$ \\
& & N-America & Canada & 3 \\
& & USA & 20 \\
& & & Total & $\mathbf{2 3}$ \\
& & & Argentina & 1 \\
& & & Brazil & 3 \\
& & & Total & $\mathbf{4}$ \\
\hline
\end{tabular}

\section{References}

Ahrné K, Bengtsson J, Elmqvist T (2009) Bumble bees (Bombus spp) along a gradient of increasing urbanization. PLoS ONE 4:e5574

Amiet F (1996) Hymenoptera Apidae, 1. Teil. Allgemeiner Teil, Gattungsschlüssel—Die Gattungen ApisBombus und Psithyrus. Insect Helv 12:1-98

Amiet F, Herrmann M, Müller A, Neumeyer R (2001) Apidae 3: Halictus, Lasioglossum. Fauna Helv 6:1-208

Amiet F, Herrmann M, Müller A, Neumeyer R (2004) Apidae 4: Anthidium, Chelostoma, Coelioxys, Dioxys, Heriades, Lithurgus, Megachile, Osmia, Stelis. Fauna Helv 9:1-273

Amiet F, Herrmann M, Müller A, Neumeyer R (2007) Apidae 5: Ammobates, Ammobatoides, Anthophora, Biastes, Ceratina, Dasypoda, Epeoloides, Epeolus, Eucera, Macropis, Melecta, Melitta, Nomada, Pasites, Tetralonia, Thyreus, Xylocopa. Fauna Helv 20:1-356

Amiet F, Müller A, Neumeyer R (2012) Apidae 2: Colletes, Dufourea, Hylaeus, Nomia, Nomioides, Rhophitoides, Rophites, Sphecodes, Systropha. Fauna Helv 4:1-210

Antonini Y, Martins RP, Aguiar LM, Loyola RD (2013) Richness, composition and trophic niche of stingless bee assemblages. Urban Ecosyst 16:527-541 
Araújo ED, Costa M, Chaud-Netto J, Fowler HG (2004) Body size and flight distance in stingless bees. Braz J Biol 64:563-568

Aronson MFJ et al (2016) Hierarchical filters determine community assembly of urban species pools. Ecology 97:2952-2963

Baldock KCR, Goddard MA, Hicks DM, Kunin WE, Mitschunas N, Morse M, Osgathorpe LM, Potts SG, Robertson KM, Scott AV, Staniczenko PAP, Stone GN, Vaughan IP, Memmott J (2019) A systems approach reveals urban pollinator hotspots and conservation opportunities. Nat Ecol Evol 3:363-373

Baldock KCR, Goddard MA, Hicks DM, Kunin WE, Mitschunas N, Osgathorpe LM, Potts SG, Robertson KM, Scott AV, Stone GN, Vaughan IP, Memmott J (2015) Where is the UK's pollinator biodiversity? The importance of urban areas for flower-visiting insects. Proc R Soc Lond B 282:2014-2849

Banaszak-Cibicka W (2014) Are urban areas suitable for thermophilic and xerothermic bee species (Hymenoptera: Apoidea: Apiformes)? Apidologie 45:145-155

Banaszak-Cibicka W, Żmihorski M (2012) Wild bees along an urban gradient: winners and losers. J Insect Conserv 16:331-343

Banaszak-Cibicka W, Twerd L, Fliszkiewicz M, Giejdasz K, Langowska A (2018a) City parks vs. natural areas: is it possible to preserve a natural level of bee richness and abundance in a city park? Urban Ecosyst 21:599-613

Banaszak-Cibicka W, Fliszkiewicz M, Langowska A, Żmihorski M (2018b) Body size and wing asymmetry in bees along an urbanization gradient. Apidologie 49:297-306

Banaszak-Cibicka W, Ratyńska H, Dylewski Ł (2016) Features of urban green space favourable for large and diverse bee populations (Hymenoptera: Apoidea: Apiformes). Urban For Urban Green 20:448-452

Bartomeus I, Ascher JS, Gibbs J, Danforth BN, Wagner DL, Hedtke SM, Winfree R (2013) Historical changes in northeastern US bee pollinators related to shared ecological traits. PNAS 110:4656-4660

Blackmore LM, Goulson D (2014) Evaluating the effectiveness of wildflower seed mixes for boosting floral diversity and bumblebee and hoverfly abundance in urban areas. Insect Conserv Divers 7:480-484

Braaker S, Obrist MK, Ghazoul J, Moretti M (2017) Habitat connectivity and local conditions shape taxonomic and functional diversity of arthropods on green roofs. J Anim Ecol 86:521-531

Brosseau P-M, Gravel D, Handa IT (2018) On the development of a predictive functional trait approach for studying terrestrial arthropods. J Anim Ecol 87:1209-1220

Buchholz S, Hannig K, Möller M, Schirmel J (2018) Reducing management intensity and isolation as promising tools to enhance ground-dwelling arthropod diversity in urban grasslands. Urban Ecosyst 21:1139-1149

Buchholz S, Gathof AK, Grossmann AJ, Kowarik I, Fischer L (2020) Wild bees in urban grasslands: urbanisation, functional diversity and species traits. Landsc Urban Plan 196:103731

Cane JH (2005) Bees' needs challenged by urbanization. In: Johnson EA, Klemens MW (eds) Nature in fragments: the legacy of sprawl. Columbia University Press, New York, pp 109-124

Cane JH, Minckley RL, Kervin LJ, Roulston TH, Williams NM (2006) Complex responses within a desert bee guild (Hymenoptera: Apiformes) to urban habitat fragmentation. Ecol Appl 16:632-644

Cardoso MC, Goncalves RB (2018) Reduction by half: the impact on bees of 34 years of urbanization. Urban Ecosyst 21:943-949

Carper AL, Adler LS, Warren PS, Irwin RE (2014) Effects of suburbanization on forest bee communities. Environ Entomol 43:253-262

Classen A, Steffan-Dewenter I, Kindeketa WJ, Peters MK (2017) Integrating intraspecific variation in community ecology unifies theories on body size shifts along climatic gradients. Funct Ecol 31:768-777

Coddington JA, Griswold CE, Silva D, Peñaranda E, Larcher SF (1991) Designing and testing sampling protocols to estimate biodiversity in tropical ecosystems. In: Dudley E (ed) The Unity of Evolutionary Biology: Proceedings of the fourth international congress of systematic and evolutionary biology 2 , pp 44-60

Colla SR, MacIvor JS (2016) Questioning public perception, conservation policy, and recovery actions in honeybees in North America. Conserv Biol 5:1202-1204

Dallimer M, Tang Z, Gaston KJ, Davies ZG (2016) The extent of shifts in vegetation phenology between rural and urban areas within a human-dominated region. Ecol Evol 6:1942-1953

Deguines N, Julliard R, de Flores M, Fontaine C (2016) Functional homogenization of flower visitor communities with urbanization. Ecol Evol 6:1967-1976

Des Roches S, Post DM, Turley NE, Bailey JK, Hendry AP, Kinnison MT, Schweitzer J, Palkovacs EP (2018) The ecological importance of intraspecific variation. Nat Ecol Evol 2:57-64

Díaz S, Purvis A, Cornelissen JH, Mace GM, Donoghue MJ, Ewers RM, Jordano P, Pearse WD (2013) Functional traits, the phylogeny of function, and ecosystem service vulnerability. Ecol Evol 3:2958-2975. https://doi.org/10.1002/ece3.601 
Didham RK, Leather SR, Basset Y (2016) Circle the bandwagons-challenges mount against the theoretical foundations of applied functional trait and ecosystem service research. Insect Conserv Diver 9:1-3

Dray S, Dufour AB (2007) The ade4 package: implementing the duality diagram for ecologists. J Stat Softw 22:1-20

Dray S, Dufour AB, Chessel D (2007) The ade4 package-II: Two-table and K-table methods. R News 7:47-52

Dray S et al (2014) Combining the fourth-corner and the RLQ methods for assessing trait responses to environmental variation. Ecology 95:14-21

Dylewski L, Maćkowiak L, Banaszak-Cibicka W (2019) Are all urban green spaces a favourable habitat for pollinator communities? Bees, butterflies and hoverflies in different urban green areas. Ecol Entomol 44:678-689

Edelsparre AH, Shahid A, Fitzpatrick MJ (2018) Habitat connectivity is determined by the scale of habitat loss and dispersal strategy. Ecol Evol 11:5508-5514

Egerer M, Cecala JM, Cohen H (2020) Wild bee conservation within urban gardens and nurseries: effects of local and landscape management. Sustainability 12:293

Eggenberger H, Frey D, Pellissier L, Ghazoul J, Fontana S, Moretti M (2019) Urban bumblebees are smaller and more phenotypically diverse than their rural counterparts. J Anim Ecol 88:1522-1533

Fetridge ED, Ascher JS, Langellotto GA (2008) The bee fauna of residential gardens in a suburb of New York city (Hymenoptera: Apoidea). Ann Entomol Soc Am 101:1067-1077

Fischer LK, Eichfeld J, Kowarik I, Buchholz S (2016) Disentangling urban habitat and matrix effects on wild bee species. PeerJ 4:e2729

Fitch G, Glaum P, Simao M-C, Vaidya C, Matthijs J, Iuliano B, Perfecto I (2019) Changes in adult sex ratio in wild bee communities are linked to urbanization. Sci Rep 9:3767

Fortel L, Henry M, Guibaud L, Guirao AL, Kuhlmann M, Mouret H, Rollin O, Vaissière BE (2014) Decreasing abundance, increasing diversity and changing structure of the wild bee community (Hymenoptera: Anthophila) along an urbanization gradient. PLoS ONE 9:e104679

Francis RA, Chadwick MA (2013) Urban ecosystems: understanding the human environment. Routledge, London

Frankie GW, Thorp RW, Schindler M, Hernandez J, Ertter B, Rizzardi M (2005) Ecological patterns of bees to host ornamental flowers in two northern California cities. J Kans Entomol Soc 78:227-246

Fründ J, Zieger SL, Tscharntke T (2013) Response diversity of wild bees to overwintering temperatures. Oecologia 173:1639-1648

Gago EJ, Roldan J, Pacheco-Torres R, Ordónez J (2013) The city and urban heat islands: a review of strategies to mitigate adverse effects. Renew Sustain Energy Rev 25:749-758

Geslin B, Le Féon V, Folschweiller M, Flacher F, Carmignac D, Motard E, Perret S, Dajoz I (2016a) The proportion of impervious surfaces at the landscape scale structures wild bee assemblages in a densely populated region. Ecol Evol 6:6599-6615

Geslin B, Le Féon V, Kuhlmann M, Vaissière DI (2016b) The bee fauna of large parks in downtown Paris, France. Ann Soc Entomol Fr. https://doi.org/10.1080/00379271.2016.1146632

Gill RJ, Baldock KCR, Brown MJF, Cresswell JE, Dicks LV, Fountain MT, Garratt MPD, Gough LA, Heard MS, Holland JM, Ollerton J, Stone GN, Tang CQ, Vanbergen AJ, Vogler AP, Woodward G, Arce AN, Boatman ND, Brand-Hardy R, Breeze TD, Green M, Hartfield CM, O'Connor RS, Osborne JL, Phillips J, Sutton PB, Potts SG (2016) Chapter four: protecting an ecosystem service: approaches to understanding and mitigating threats to wild insect pollinators. In: Woodward G, Bohan DA (eds) Advances in ecological research. Academic Press, Cambridge, pp 135-206

Glaum P, Simao MC, Vaidya C, Fitch G, Iulinao B (2017) Big city Bombus: using natural history and landuse history to find significant environmental drivers in bumble-bee declines in urban development. R Soc Open Sci 4:170156

Gonzalez VH, Park KE, Çakmak I, Hranitz JM, Barthell JF (2016) Pan traps and bee body size in unmanaged urban habitats. J Hymenopt Res 51:241-247

Gotlieb A, Hollender Y, Mandelik Y (2011) Gardening in the desert changes bee communities and pollination network characteristics. Basic Appl Ecol 12:310-320

Goulson D, Nicholls E, Botías C, Rotheray EL (2015) Bee declines driven by combined stress from parasites, pesticides, and lack of flowers. Science 347:1435

Greenleaf SS, Williams NM, Winfree R, Kremen C (2007) Bee foraging ranges and their relationship to body size. Oecologia 153:589-596

Guenat S, Kunin WE, Dougill AJ, Dallimer M (2019) Effects of urbanisation and management practices on pollinators in tropical Africa. J Appl Ecol 56:214-224

Hall DM, Camilo GR, Tonietto RK, Ollerton J, Ahrné K, Arduser M, Ascher JS, Baldock KCR, Fowler R, Frankie G, Goulson D, Gunnarsson B, Hanley ME, Jackson JI, Langellotto G, Lowenstein D, Minor 
ES, Philpott SM, Potts SG, Sirohi MH, Spevak EM, Stone GN, Threlfall CG (2017) The city as a refuge for insect pollinators. Conserv Biol 31:24-29

Hamblin AL, Youngsteadt E, Frank SD (2018) Wild bee abundance declines with urban warming, regardless of floral density. Urban Ecosyst 21:419-428

Hamblin AL, Youngsteadt E, López-Uribe MM, Frank SD (2017) Physiological thermal limits predict differential responses of bees to urban heat-island effects. Biol Lett 13:20170125

Harrison T, Winfree R (2015) Urban drivers of plant-pollinator interactions. Funct Ecol 29:879-888

Harrison T, Gibbs J, Winfree R (2019) Anthropogenic landscapes support fewer rare bee species. Landsc Ecol 34:967-978

Harrison T, Gibbs J, Winfree R (2018) Forest bees are replaced in agricultural and urban landscapes by native species with different phenologies and life-history traits. Glob Change Biol 24:287-296

Hausmann SL, Petermann JS, Rolff J (2016) Wild bees as pollinators of city trees. Insect Conserv Divers 9:97-107

Hernandez JL, Frankie GW, Thorp RW (2009) Ecology of urban trees: a review of current knowledge and directions for future study. CATE 2:1-15

Hinners SJ, Kearns CA, Wessman CA (2012) Roles of scale, matrix, and native habitat in supporting a diverse suburban pollinator assemblage. Ecol Appl 22:1923-1935

Hoffmann MM, Renner SS (2018) Bee species recorded between 1992 and 2017 from green roofs in Asia, Europe, and North America, with key characteristics and open research questions. Apidologie 49:307-313

Homburg K, Homburg N, Schäfer F, Schuldt A, Assmann T (2014) Carabids.org: a dynamic online database of ground beetle species traits (Coleoptera, Carabidae). Insect Conserv Diver 7:195-205

Hülsmann M, von Wehrden H, Klein A-M, Leonhardt SD (2015) Plant diversity and composition compensate for negative effects of urbanization on foraging bumble bees. Apidologie 46:760-770

Hung K-LJ, Ascher JS, Davids JA, Holway DA (2019) Ecological filtering in scrub fragments restructures the taxonomic and functional composition of native bee assemblages. Ecology 100:e02654

Iwasa Y, Yamauchi A, Nozoe S (1992) Optimal seasonal timing of univoltine and bivoltine insects. Ecol Res 7:55-62

Jędrzejewska-Szmek K, Zych M (2013) Flower-visitor and pollen transport networks in a large city: structure and properties. Arthropod Plant Interact 7:503-516

Kearns CA, Oliveras DM (2009) Environmental factors affecting bee diversity in urban and remote grassland plots in Boulder, Colorado. J Insect Conserv 13:655-665

Kotze J, Venn S, Niemelä SJ (2011) Effects of urbanization on the ecology and evolution of arthropods. In: Niemela J (ed) Urban ecology. Patterns, processes, and applications. Oxford University Press, Oxford, pp 1-374

Kratschmer S, Kriechbaum M, Pachinger B (2018) Buzzing on top: Linking wild bee diversity, abundance and traits with green roof qualities. Urban Ecosyst 21:429-446

Kremen C, Williams NM, Aizen MA, Gemmill-Herren B, LeBuhn G, Minckley R, Packer L, Potts SG, Roulston T, Steffan-Dewenter I, Vázquez DP, Winfree R, Adams L, Crone EE, Greenleaf SS, Keitt TH, Klein AM, Regetz J, Ricketts TH (2007) Pollination and other ecosystem services produced by mobile organisms: a conceptual framework for the effects of land-use change. Ecol Lett 10:299-314

Laliberté E, Legendre P (2010) A distance-based framework for measuring functional diversity from multiple traits. Ecology 91:299-305

Laliberté E, Legendre P, Shipley B (2014) FD: measuring functional diversity from multiple traits, and other tools for functional ecology. R package version 1.0-12

Lavorel S, Garnier E (2002) Predicting changes in community composition and ecosystem functioning from plant traits: revisiting the holy grail. Funct Ecol 16:545-556

Leong M, Ponisio LC, Kremen C, Thorp RW, Roderick GK (2016) Temporal dynamics influenced by global change: bee community phenology in urban, agricultural, and natural landscapes. Glob Change Biol 22:1046-1053

Lerman SB, Milam J (2016) Bee fauna and floral abundance within lawn-dominated suburban yards. Ann Entomol Soc Am 109:713-723

Liebergesell M, Reu B, Stahl U, Freiberg M, Welk E, Kattge J, Cornelissen JHC, Peñuelas J, Wirth C (2016) Functional resilience against climate-driven extinctions: comparing the functional diversity of European and North American Tree Floras. PLoS ONE 11:e0148607

Loreau M (2010) Linking biodiversity and ecosystems: towards a unifying ecological theory. Philos Trans R Soc Lond B 365:49-60

Lowenstein DM, Matteson KC, Minor ES (2015) Diversity of wild bees supports pollination services in an urbanized landscape. Oecologia 179:811-821 
Lowenstein DM, Matteson KC, Xiao I, Silva AM, Minor ES (2014) Humans, bees, and pollination services in the city: the case of Chicago, IL (USA). Biodivers Conserv 23:2857-2874

Magurran AE, McGill BJ (eds) (2011) Biological diversity: frontiers in measurement and assessment. Oxford University Press, Oxford

Martins KT, Gonzalez A, Lechowicz MJ (2017) Patterns of pollinator turnover and increasing diversity associated with urban habitats. Urban Ecosyst 20:1359-1371

Mason NWH, Mouillot D, Lee WG, Bastow Wilson J (2005) Functional richness, functional evenness and functional divergence: the primary components of functional diversity. Oikos 111:112-118

Matteson KC, Ascher JS, Langellotto GA (2008) Bee richness and abundance in New York city urban gardens. Ann Entomol Soc Am 101:140-150

Mazzeo NM, Torretta JP (2015) Wild bees (Hymenoptera: Apoidea) in an urban botanical garden in Buenos Aires, Argentina. Stud Neotrop Fauna E. https://doi.org/10.1080/01650521.2015.1093764

McCluney KE, Burdine JD, Frank SD (2017) Variation in arthropod hydration across US cities with distinct climate. J Urban Ecol. https://doi.org/10.1093/jue/jux003

McFrederick QS, LeBuhn G (2006) Are urban parks refuges for bumble bees Bombus spp. (Hymenoptera: Apidae)? Biol Conserv 129:372-382

McIntyre NE, Hostetler ME (2001) Effects of urban land use on pollinator communties in a desert metropolis. Basic Appl Ecol 2:209-218

Molumby A, Przybylowicz T (2012) Bees (Hymenoptera: Apoidea) of the Chicago area: diversity and habitat use in an urbanized landscape. Great Lakes Entomol 45:79-98

Moretti M, Dias ATC, De Bello F, Altermatt F, Chown SL, Azcárate FM, Bell JR, Fournier B, Hedde M, Hortal J, Ibanez S, Öckinger E, Sousa JP, Ellers J, Berg MP (2017) Handbook of protocols for standardized measurement of terrestrial invertebrate functional traits. Funct Ecol 31:558-567

Moroń D, Grześ IM, Skórka P, Szentgyörgyi H, Laskowski R, Potts SG, Woyciechowski M (2012) Abundance and diversity of wild bees along gradients of heavy metal pollution. J Appl Ecol 49:118-125

Neame LA, Grisworld T, Elle E (2013) Pollinator guilds respond differently to urban habitat fragmentation in an oak-savanah ecosystem. Insect Conserv Divers 6:57-66

Normandin É, Vereecken NJ, Buddle CM, Fournier V (2017) Taxonomic and functional trait diversity of wild bees in different urban settings. PeerJ 5:e3051

Oksanen L (2001) Logic of experiments in ecology: is pseudoreplication a pseudoissue? Oikos 94:27-38

Oliver TH, Heard MS, Isaac NJB, Roy DB, Procter D, Eigenbrod F, Freckleton R, Hector A, Orme CDL, Petchey OL, Proença V, Raffaelli D, Suttle KB, Mace GM, Martín-López B, Woodcock BA, Bullock JM (2015) Biodiversity and resilience of ecosystem functions. Trends Ecol Evol 30:673-684. https:// doi.org/10.1016/j.tree.2015.08.009

Ollerton J (2017) Pollinator Diversity: Distribution, Ecological Function, and Conservation. Annu Rev Ecol Evol Syst 48:353-376

Page RE, Scheiner R, Erber J, Amdam GV (2006) The development and evolution of division of labor and foraging specialization in a social insect. Curr Top Dev Biol 74:253-286

Pardee GL, Philpott SM (2014) Native plants are the bee's knees. Urban Ecosyst 17:641-659

Petchey OL, Gaston KJ (2006) Functional diversity: back to basics and looking forward. Ecol Lett 9:741-758

Phillips BB, William A, Osborne JL, Shaw RF (2018) Shared traits make flies and bees effective pollinators of oilseed rape (Brassica napus L.). Basic Appl Ecol 32:66-76

Quistberg RD, Bichier P, Philpott SM (2016) Landscape and local correlates of bee abundance and species richness in urban gardens. Environ Entomol 45:592-601

Ropars L, Dajoz I, Fontaine C, Muratet A, Geslin B (2019) Wild pollinator activity negatively related to honey bee colony densities in urban context. PLoS ONE 14:1-16

Roulston T, Smith S, Brewster A (2007) A comparison of pan trap and intensive net sampling techniques for documenting a bee (Hymenoptera: Apiformes) fauna. J Kansas Entomol Soc 80(2):179-181

Salisbury A, Armitage J, Bostock H, Perry J, Tatchell M, Thompson K (2015) Enhancing gardens as habitats for flower-visiting aerial insects (pollinators): should we plant native or exotic species? J Appl Ecol 52:1156-1164

Scheiner SM, Kosman E, Presley SJ, Willig MR (2017) Decomposing functional diversity. Methods Ecol Evol 8:809-820

Schirmel J, Blindow I, Buchholz S (2012) Life-history trait and functional diversity patterns of ground beetles and spiders along a coastal heathland successional gradient. Basic Appl Ecol 13:606-614

Schirmel J, Thiele J, Entling MH, Buchholz S (2016) Trait composition and functional diversity of spiders and carabids in linear landscape elements. Agric Ecosyst Environ 235:318-328 
Schmid-Hempel R, Schmid-Hempel P (1998) Colony performance and immunocompetence of a social insect, Bombus terrestris, in poor and variable environments. Funct Ecol 12:22-30

Simao M-CM, Matthijs J, Perfecto I (2018) Experimental small-scale flower matches increase species density but not abundance of small urban bees. J Appl Ecol 55:1759-1768

Sirohi MH, Jackson J, Edwards M, Ollerton J (2015) Diversity and abundance of solitary and primitively eusocial bees in an urban centre: a case study from Northampton (England). J Insect Conserv $19: 487-500$

Sivakoff FS, Prajzner SP, Gardiner MM (2018) Unique bee communities within vacant lots and urban farms result from variation in surrounding urbanization intensity. Sustainability 10:1926

Stang M, Klinkhamer PGL, Van Der Meijden E (2006) Size constraints and flower abundance determine the number of interactions in a plant-flower visitor web. Oikos 112:111-121

Stelzer RJ, Chittka L, Carlton M, Ings TC (2010) Winter active bumblebees (Bombus terrestris) achieve high foraging rates in urban Britain. PLoS ONE 5:e9559

Sutcliffe GH, Plowright RC (1988) The effects of food supply on adult size in the bumble bee Bombus terricola Kirby (Hymenoptera: Apidae). Can Entomol 120:1051-1058

Threlfall CG, Walker K, Williams NS, Hahs AK, Mata L, Stork N, Livesley SJ (2015) The conservation value of urban green space habitats for Australian native bee communities. Biol Conserv 187:240-248

Turo KJ, Gardiner MM (2019) From potential to practical: conserving bees in urban public green spaces. Fron Ecol Environ 17:167-175

Twerd L, Banaszak-Cibicka W (2019). Wastelands: Their attractiveness and im-portance for preserving the diversity of wild bees in urban areas. J Ins Conserv

Violle C, Navas ML, Vile D, Kazakou E, Fortunel C, Hummel I, Garnier E (2007) Let the concept of trait be functional! Oikos 116:882-892

von der Lippe M, Buchholz S, Hiller A, Seitz B, Kowarik I (2020) CityScapeLab Berlin: a research platform for untangling urbanization effects on biodiversity. Sustainability 12:2565

Warzecha D, Diekötter T, Wolters V, Jauker F (2016) Intraspecific body size increases with habitat fragmentation in wild bee pollinators. Landsc Ecol 31:1449-1455

Westrich P (2019) Die Wildbienen Deutschlands. Verlag Eugen, Ulmer

Wong MKL, Guénard B, Lewis OT (2019) Trait-based ecology of terrestrial arthropods. Biol Rev 94:999-1022

Wray JC, Neame LA, Elle E (2014) Floral resources, body size, and surrounding landscape influence bee community assemblages in oak-savannah fragments. Ecol Entomol 39:83-93

Wu P, Axmacher JC, Song X, Zhang X, Huanli X, Chen C, Yu Z, Liu Y (2018) Effects of plant diversity, vegetation composition, and habitat type on different functional trait groups of wild bees in rural Beijing. J Insect Sci 18:1-9

Yachi S, Loreau M (1999) Biodiversity and ecosystem productivity in a fluctuating environment: the insurance hypothesis. Proc Natl Acad Sci USA 96:1463-1468

Zanette LRS, Martins RP, Ribeiro SP (2005) Effects of urbanization onEnviron. Entomol. Neotropical wasp and bee assemblages in a Brazilian metropolis. Landsc Urban Plan 71:105-121

Zurbuchen A, Müller A (2012) Wildbienenschutz: von der Wissenschaft zur Praxis. Haupt Verlag, Bern

Publisher's Note Springer Nature remains neutral with regard to jurisdictional claims in published maps and institutional affiliations.

\section{Affiliations}

\section{Sascha Buchholz ${ }^{1,2} \cdot$ Monika H. Egerer ${ }^{1,2}$}

Monika H. Egerer

monika.egerer@tu-berlin.de

1 Department of Ecology, Technische Universität Berlin, Rothenburgstr. 12, 12165 Berlin, Germany

2 Berlin-Brandenburg Institute of Advanced Biodiversity Research (BBIB), 14195 Berlin, Germany 